\title{
Multi-scale characterization of pores in shale by nitrogen adsorption and high pressure mercury methods
}

\author{
Jlan Xiaofei ${ }^{1,2} a^{*}$, Liu Renhe ${ }^{2,3 b}$, Tang Shuheng ${ }^{1}$, Jia Lingxiao ${ }^{1}$, Wang Yuwan ${ }^{4}$, \\ Zhang $\mathrm{Yao}^{4}$, Xin $\mathrm{Di}^{1}$, \\ ${ }^{1}$ China University of Geosciences, Beijing 100083, China \\ ${ }^{2}$ National Energy Shale Gas R\&D (Experimental) Center, Langfang, Hebei 065007, China \\ ${ }^{3}$ Research Institute of Petroleum Exploration and Development-LangFang, Hebei 065007, China \\ ${ }^{4}$ Chengdu University of Technology, Chengdu, Sichuan 610059, China \\ a872411052@qq.com, ${ }^{\mathrm{b}}$ liurenhe69@petrochina.com.cn
}

\begin{abstract}
Keywords: Liaohe Depression; Taiyuan Formation; shale; pore; high-pressure mercury injection; Nitrogen adsorption

Abstract: High pressure mercury and nitrogen adsorption had been conducted on outcrop and core samples for studying the pore structure characteristics about shale in eastern uplift of Liaohe depression. The results showed that: The pores mainly are nano-scale and irregular in size and arrangement. The nitrogen adsorption curves about shale are type II, and the adsorption loop can be divided into 3 types: type P1 represents the pores dominated by airtight pores with one end closed; type P2 demonstrates the pores dominated by ink-bottle pores and airtight pores with one end closed; type P3 represents the pores dominated by open pores and airtight pores with one end closed. The distribution of pores has two peaks that the pores' average diameter is $4 \mathrm{~nm}$ and $6 \mu \mathrm{m}$ respectively. The mesoporous and macroporous pore volume accounted for $85 \%$ of all, and they provide the main place for free gas. The surface area of mesopore and micropore accounted for $97.86 \%$ of all, and they enhance the adsorption capacity of shale.
\end{abstract}

\section{Introduction}

Shale gas is produced from organic-rich shales, and is continuously accumulated in shale nanometer pores with a typical character of self-generation and self-storage ${ }^{[1,2]}$. Shales in our country have a series of features: old ages, frequent transformations by multiphase tectonic activity, high evolutionary proportion. The previous studies have studyed on reservoir forming and accumulation model, shale adsorption properties and gas preserving conditions on marine shale gas in South China. Compared to marine shales, continental shales have characteristics of thin thickness, low brittle mineral content, high clay mineral content and low pressure. With the help of $\mathrm{CO}_{2}$-fracturing technology, the deliverability building of demonstration plot for continental shale gas is steadily progressing. Nevertheless, the current study for transitional facies shale is still relatively litte. Because of thin thickness, rapid changes of lithofacies in transitional facies shale, the potential of shale gas is controversial. Moreover, the kerogen types of marine shale in North American and South China are mainly Typel and Typell. The research about Type III source rock whether has a large potiental for shale gas or not is less. The upper Carboniferous Taiyuan formation shale in the eastern uplift of Liaohe Depresstion is Type III source rock. Apparently, the study has practical and theoretical significance.

Shale gas in the study area is still during the exploration phase. The previous researches were mainly about shale geochemical characteristics, gas producing capacity, gas content and tectonic evaluation ${ }^{[3-7]}$. Economically, we need to transform the unconventional reservoir to be "man-made" conventional reservoir ${ }^{[8-11]}$. Therefore, the research about the upper Carboniferous Taiyuan Formation shale has great significance on developing shale gas efficiently. 


\section{Geological Setting}

Adjacent to Liaodong fold belt and Yanshan depression, Liaohe Depression lies in the east of North China Plate. Liaohe Depression is a Cenozoic basin located in central and northern region of Bohai Basin. Liaohe Depression presents a structural feature with three depressions and three uplifts which are western uplift, western depression, Damintun depression, central uplift, eastern depression and eastern uplift ${ }^{[5,7]}$ (Fig.1). The eastern uplift locates on the east of Liaohe Depression and it is about $80 \mathrm{~km}$ wide from north to south, $20 \mathrm{~km}$ wide from east to west.
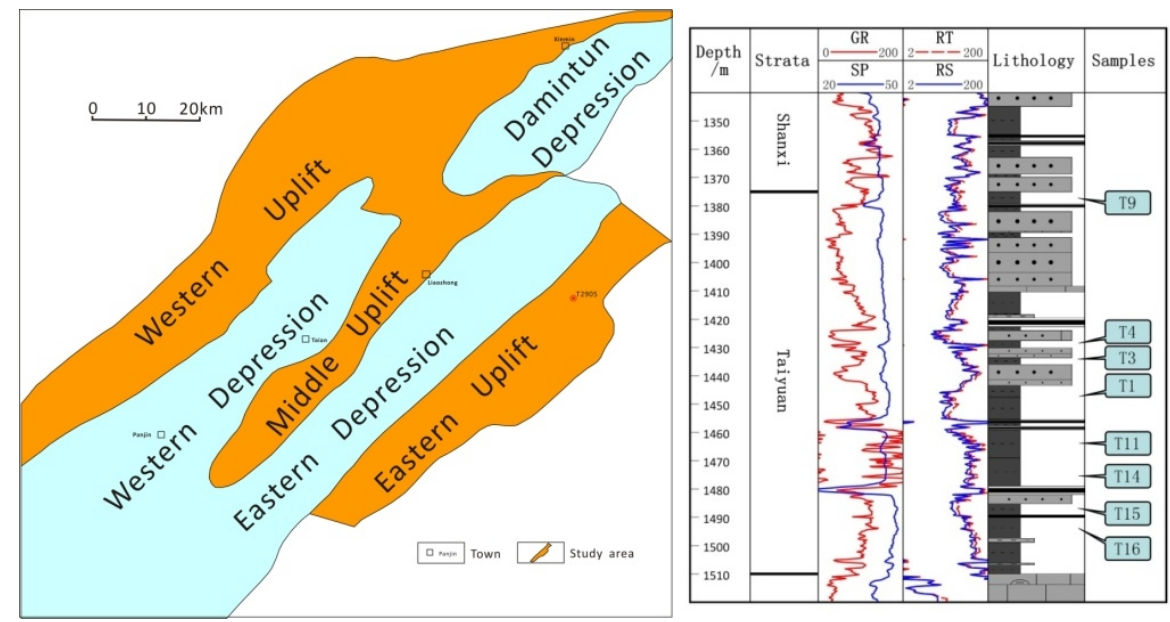

Fig.1 Location of T2905 core samples and eastern uplift in Liaohe basin

Depending on the drilling data, the thickness of Taiyuan formation in eastern uplift is $122.9 \mathrm{~m} \sim 171.3 \mathrm{~m}$ and the shale thickness is $48 \mathrm{~m} \sim 87.4 \mathrm{~m}$. The core samples in this paper were chosen from Well 2905. The samples average TOC is $3 \%$. The samples $R_{o}$ is between $2.1 \%$ and $2.7 \%$, which is in the phase of dry gas $\left(\mathrm{R}_{\mathrm{o}}>1.4 \%\right)$. The kerogen type is Type III and the vitrinite is nearly $77 \%$.

The paper carried out high pressure mercury injection and $\mathrm{N}_{2}$ adsorption test on these samples. Based on Petroleum Industry Standard SY/T5346-2005, the high-pressure mercury injection was accomplished by Experimental Research Center of Wuxi Petroleum Geology Research Institute of PEPRIS. The machine is AutoPore IV 9520. Based on Petroleum Industry Standard SY/T6154-1995, the $\mathrm{N}_{2}$ adsorption was completed by CNPC Key Laboratory for unconventional oil and gas with machine Thermo SURFER (FCG-032). The conditions are $120^{\circ} \mathrm{C}$ and $5 \mathrm{~h}$ for vacuum pumping under $1.0 \times 10^{-3} \mathrm{~Pa}$.

\section{Pore Characteristics}

\section{Pore Morphology}

Many scholars have carried out an amount of researches on pore of shale reservoir: pore of shale is mainly micron-nanometer sized pore. The accumulation space of shale is greatly related to the development of pore ${ }^{[12-14]}$. Depending on the pore size, shale pores are classified three types by Zou Caineng ${ }^{[15]}$ : millimeter-level $(>1 \mathrm{~mm})$, micron-level $(1 \sim 1000 \mu \mathrm{m})$ and nanometer-level $(<1 \mu \mathrm{m})$. Furthermore, the IUPCU subdivides nanometer-level pore into macropore $(>50 \mathrm{~nm})$, mesopore $(2 \sim 50 \mathrm{~nm})$, micropore $(<2 \mathrm{~nm})^{[16]}$.

According to the theory of adsorption and coagulation, the curve of adsorption and desorption measured by adsorption-desorption experiments on the solids with capillary pore may emerge overlap and separate. It will generate adsorption loop when the branches of adsorption and desorption separate, and the shape of adsorption loop is partly related to pore structure ${ }^{[17-19]}$.

The morphologies of $\mathrm{N}_{2}$ adsorption curves about different samples in this paper are different but similar(Fig.2), and all of the morphologies belong to Curve II that looks reverse " $S$ " [17]. At low 
pressure phase, the curve rises slowly with a slight-convex trend and it means the transition from monomolecular-layer adsorption to polymolecular-layer adsorption. The middle section of curve rises slowly with pressure and there is just polymolecular-layer adsorption for this phase. The adsorption curve goes up drastically at high pressure phase. Finally, the curve doesn't present a phenomenon of adsorption saturation with a pressure approaching to saturated vapor pressure, and it means the occurrence of capillary condensation which causes the drastic increase of adsorbance with the filling of macropore. Therefore the samples in this context contain a certain number of mesopore and macropore.

T16

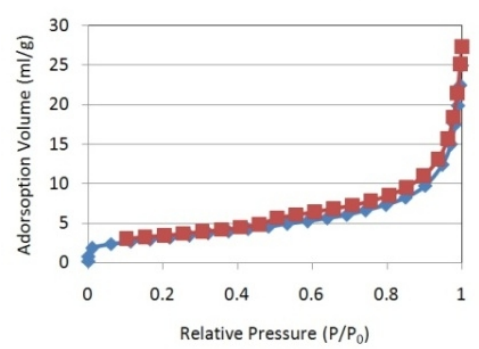

T1

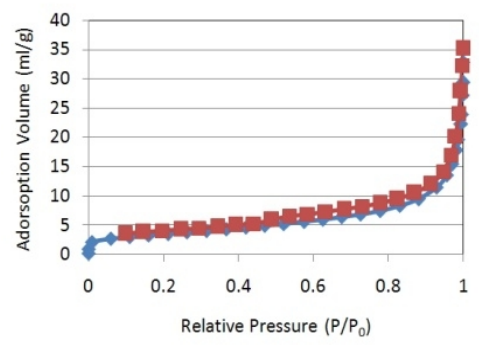

$\rightarrow$ Adsorption Curve $\rightarrow-$ Desorption Curve
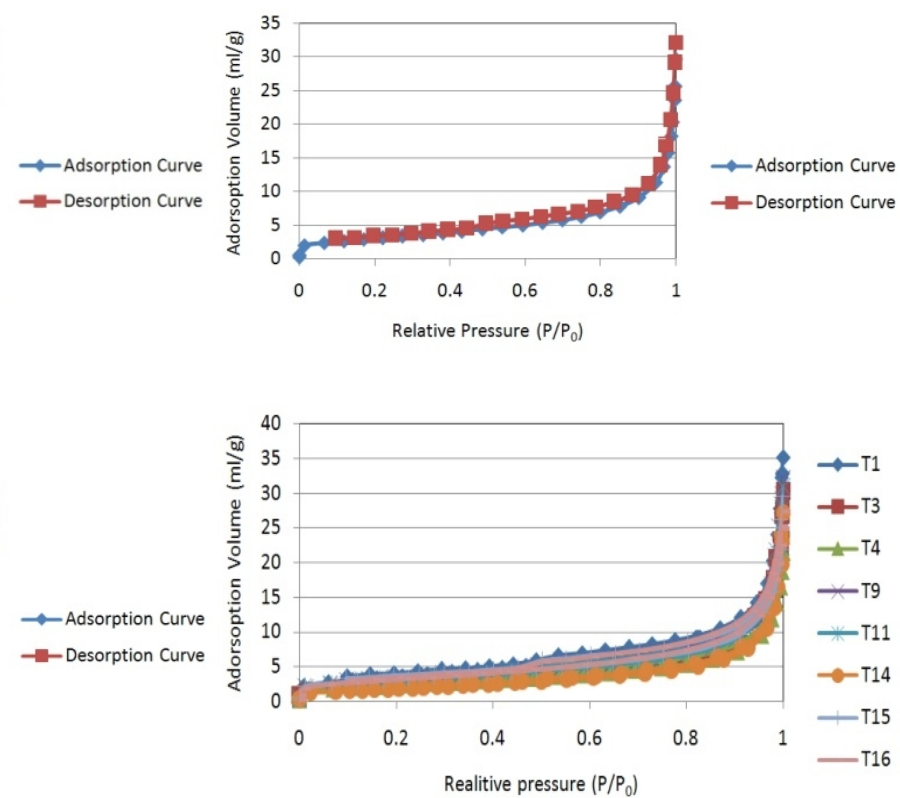

Fig.2 Adsorption isotherms of shale samples from eastern uplift of Liaohe depression

International pure chemistry and Applied Chemistry (IUPCU) divided the adsorption loop into 4 categories. $\mathrm{H}_{1}$ and $\mathrm{H}_{4}$ represent two kinds of extreme type. $\mathrm{H}_{1}$ adsorption, desorption branches in a wide range of adsorption pressure perpendicular to the axis and parallel to each other. $\mathrm{H}_{4}$ adsorption, desorption branch is horizontal in a wide range of pressure, and parallel to each other. The pores in size and arrangement are very regular often make $\mathrm{H}_{1}$. The $\mathrm{H}_{4}$ loop is generated mainly by the micropores. $\mathrm{H}_{2}, \mathrm{H}_{3}$ is a moderate case. The $\mathrm{H}_{2}$ and $\mathrm{H}_{3}$ loops are mainly generated in the sample with littery pores $[18]$

Chen Ping ${ }^{[19]}$ has divided the low temperature nitrogen adsorption loops into 3 types: Open pores, one end closed pores and Ink bottle pores. One end closed pores include cylindrical pore, parallel plate pore and wedge shaped pore. Because the relative pressure capillary condensate and evaporated is equivalent, one end closed pore' adsorption curve and desorption curves overlap and finally they don't have the adsorption loop. Open pores like four parallel sides plate pores can generate adsorption loops because of the different condensation and evaporation pressure. Ink bottle-shaped pores may have sharp decline adsorption loops on the condition of a sudden evaporation of condensed liquid.

The test samples desorption curves in the vicinity of the saturation vapor pressure is abrupt and is very flat at moderate pressure. These characteristics are similar with $\mathrm{H}_{3}$ and $\mathrm{H}_{4}$ curve recommended by IUPAC. It indicates that the shale pores are mainly micropores with complex structure, size and arrangement. Specific adsorption loops in the paper can be divided into three types: P1, P2, P3. P1: There is even no adsorption loop(Fig.2(a),(b),(c)). P1 illustrates the pores of shale mainly are one end closed pores include cylindrical pore, parallel plate pore and wedge shaped pore. P2: The adsorption loop is very small but has an inflection point (Fig.2(d), (e), (f)). The inflection point appears in the relative pressure of 0.5 . In the low pressure, the adsorption loop and desorption curves is overlapped and a small adsorption loop appears in high pressure section. It reflects the pores mainly are Ink 
bottle-shaped pores and one end closed pores.P3: The adsorption loop is obvious and has a Inflection point(Fig.2(d),(e),(f). The inflection point is in the relative pressure of 0.5. In the low pressure section, the adsorption loop and desorption curves is overlapped. It reflects the pores mainly are open large pores, Ink bottle-shaped pores.

\section{Pore Size and Distribution}

Nitrogen adsorption method mainly measures the mesopores and micropores. High-pressure mercury injection method mainly tests the macropores or even large ${ }^{[20]}$. Based on the research of pore morphology, the pores of the Taiyuan formation shale in the eastern uplift in Liaohe depression mainly are nano-scale pores. The author combined the nitrogen adsorption and high-pressure mercury injection for characterizing the pore size and distribution quantitatively.

The results of $\mathrm{N}_{2}$ adsorption show that the pores' BJH volume distribution presents bimodal phenomenon. The two peaks are at $4 \mathrm{~nm}$ and 100nm (Fig.3). And the BET pore specific surface only has one peak at $4 \mathrm{~nm}$. The two phenomenon indicate that macropores and mesopores mainly provide the most gas accumulation space and the micropores mainly contribute the specific surface.
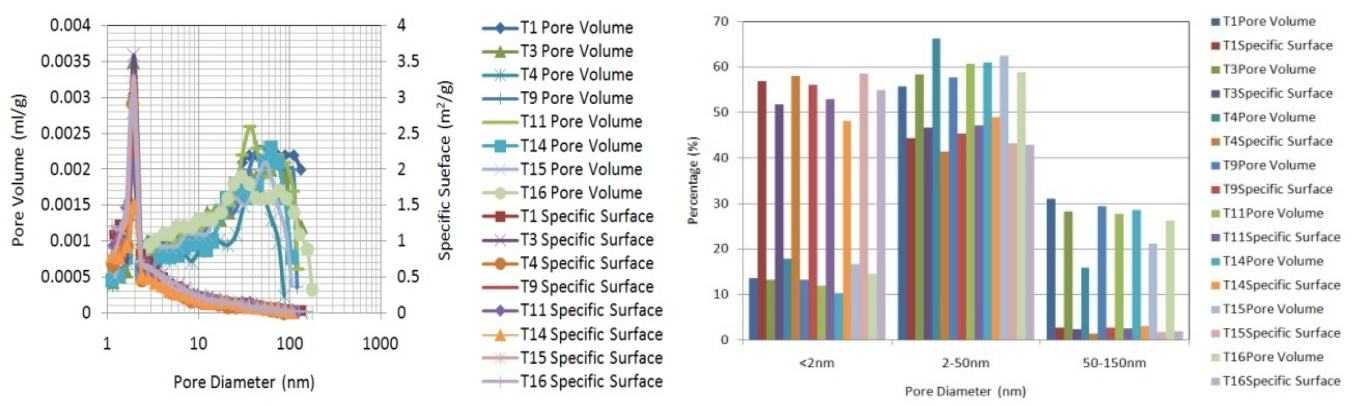

Fig.3 Pore size distribution of shale samples tested by $\mathrm{N}_{2}$ adsoption

Based on the test data (table 1), the average pore diameter is $44.62 \mathrm{~nm}$. The specific surface ranges from $6.37 \mathrm{~m}^{2} / \mathrm{g}$ to $12.55 \mathrm{~m}^{2} / \mathrm{g}$, and the average is $9.56 \mathrm{~m}^{2} / \mathrm{g}$. The BET specific surface of micropores, mesopores and macropores account for $54.85 \%, 45.58 \%, 2.14 \%$ respectively. The micropores and mesopores specific surface account for $97.86 \%$ and they enhance the adsorption capacity of shale. The pore volume ranges from $0.0234 \mathrm{ml} / \mathrm{g}$ to $0.0527 \mathrm{ml} / \mathrm{g}$, and the average is $0.0414 \mathrm{ml} / \mathrm{g}$. The BJH pore volume of micropores, mesopores and macropores account for $14.6 \%, 62.4 \%, 23.5 \%$ respectively. The macropores and mesopores volume account for $85 \%$ and they provide most gas accumulation space.

Table1 Pore size distribution of shale samples tested by $\mathrm{N}_{2}$ adsoption

\begin{tabular}{|c|c|c|c|c|c|c|c|c|c|}
\hline \multirow{2}{*}{ samples } & \multirow{2}{*}{$\begin{array}{c}\text { Pore } \\
\text { diameter } \\
{[\mathrm{nm}]}\end{array}$} & \multirow{2}{*}{$\begin{array}{l}\text { Specific } \\
\text { surface } \\
{\left[\mathrm{m}^{2} / \mathrm{g}\right]}\end{array}$} & \multirow{2}{*}{\begin{tabular}{|c} 
Pore \\
volume \\
{$[\mathrm{ml} / \mathrm{g}]$}
\end{tabular}} & \multicolumn{3}{|c|}{ Pore volume proportion [\%] } & \multicolumn{3}{|c|}{$\begin{array}{l}\text { Specific surface } \\
\text { proportion[\%] }\end{array}$} \\
\hline & & & & $<2 \mathrm{~nm}$ & $2-50 \mathrm{~nm}$ & $50-150 \mathrm{~nm}$ & $<2 \mathrm{~nm}$ & $2-50 \mathrm{~nm}$ & $50-150 \mathrm{~nm}$ \\
\hline $\mathrm{T} 1$ & 59.3454 & 12.5473 & 0.0527 & 13.699 & & 31.206 & 56.993 & 44.543 & 2.746 \\
\hline $\mathrm{T} 3$ & 46.7672 & 8.5802 & 0.0466 & 13. & & & 51.855 & 46.76 & 2.529 \\
\hline $\mathrm{T} 4$ & 30.1151 & 8.11 & 0.0311 & & & & & & 445 \\
\hline T9 & 60.1385 & 10.7 & 0.0474 & & & & 56.131 & 45. & 2.79 \\
\hline & 54.0 & & 0.0463 & & & & 52.966 & 47.1 & 2.689 \\
\hline T14 & 68.7560 & 6.5099 & 0.0394 & & & & 48.271 & 49.078 & 3.091 \\
\hline $\mathrm{T} 15$ & 38.9129 & 11.1711 & 0.0428 & & & & 58.595 & 43.33 & 1.885 \\
\hline T16 & 27.1690 & 11.2 & 0.0425 & & & & 55.038 & 43.015 & 1.964 \\
\hline WC1 & 16.2793 & 6.3737 & 0.0234 & 19.656 & & & 55.76 & 49.391 & 0.186 \\
\hline Average & 44.6180 & 9.56319 & 0.04136 & 14.646 & 2.39722 & 23.462 & 54.85711 & 45.582 & 2.147222 \\
\hline
\end{tabular}

According to high-pressure mercury injection, the large pores can be measured exactly (Fig.4). The capillary pressure curve can be divided into three stages: initial ascending stage, middle flat stage and terminal ascending stage. 
Initial ascending stage: with the increasing pressure, the mercury injection saturation increases gradually. Middle gental stage: with the increasing relative pressure, the mercury saturation increased slowly. It represents the mercury saturation improved slowly during this pressure stage. Terminal ascending atage: with the pressure further increasing, the saturation of mercury increased rapidly. The stage of terminal major mercury is flat and long. It indicates the most mercury is injected in this pressure and in another word the pores gather in small diameter range. The high pressure of injection illustrates pores diameter is tiny like nano-scale pores.

T16

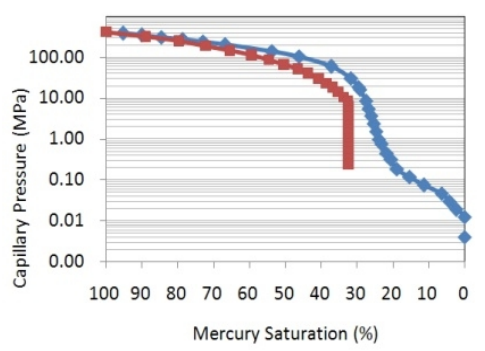

T1

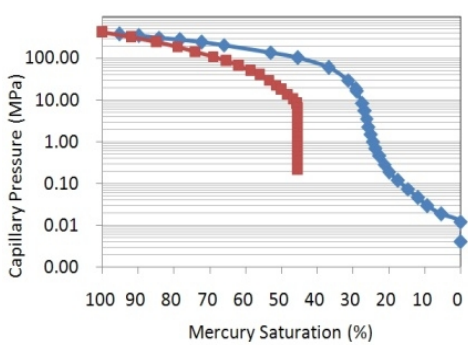

T9

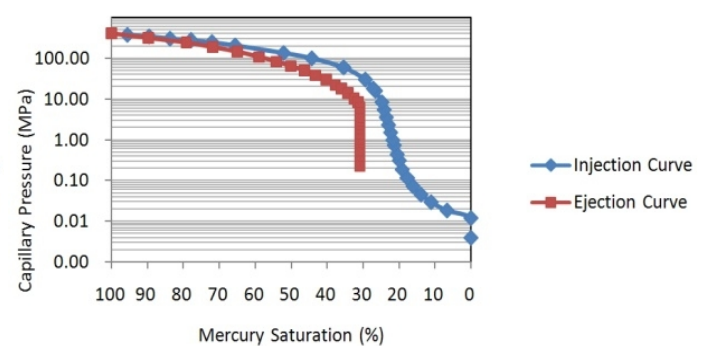

Mercury Saturation (\%)

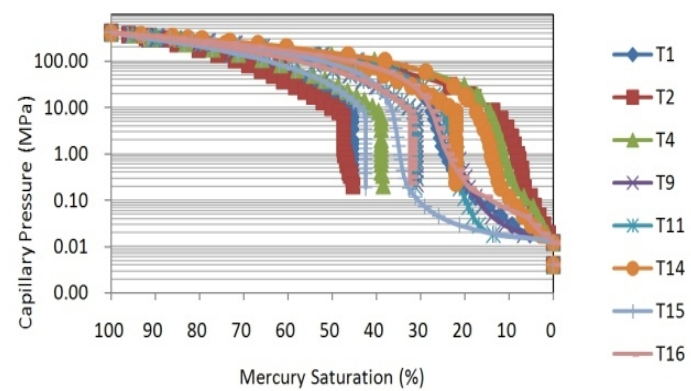

Fig.4 Capillary pressure curve of shale samples from eastern uplift of Liaohe depression

The conclusion from this research on the quantitative characteristics of capillary pressure curve (table 2): the average displacement pressure of different samples is $41.03 \mathrm{MPa}$. The displacement pressure represents the lowest pressure that mercury begin to enter the shale pores. The displacement pressure refers to the capillary pressure of the largest pore among the injected pores. The displaced pressure can be calculated by the capillary pressure curve. The average connected radius is $30 \mathrm{~nm}$. The average mercury withdrawal efficiency is $64.85 \%$. The average mercury withdrawal efficiency and connected radius shows the pores mostly are open and connected. The pores are beneficial to shale gas development.

Table 2 High pressure mercury injection characteristic parameters of Taiyuan formation samples

\begin{tabular}{|c|c|c|c|c|c|c|c|}
\hline Data & $\begin{array}{c}\text { Displacement } \\
\text { pressure } \\
(\mathrm{MPa})\end{array}$ & $\begin{array}{c}\text { Connected } \\
\text { radius } \\
(\mu \mathrm{m})\end{array}$ & $\begin{array}{c}\text { Average } \\
\text { pressure } \\
(\mathrm{MPa})\end{array}$ & $\begin{array}{c}\text { Average } \\
\text { diameter } \\
(\mu \mathrm{m})\end{array}$ & $\begin{array}{c}\text { Mercury } \\
\text { Saturation } \\
(\%)\end{array}$ & $\begin{array}{c}\text { Residual } \\
\text { saturation } \\
(\%)\end{array}$ & $\begin{array}{c}\text { Ejection } \\
\text { efficiency } \\
(\%)\end{array}$ \\
\hline T1 & 53.25669 & 0.013801 & 123.3005 & 0.005961 & 100 & 45.44427 & 54.55573 \\
\hline T2 & 24.07091 & 0.030535 & 99.5688 & 0.007382 & 100 & 45.3444 & 54.6556 \\
\hline T4 & 37.79729 & 0.019446 & 137.3208 & 0.005352 & 100 & 38.46313 & 61.53687 \\
\hline T9 & 53.27746 & 0.013796 & 127.7273 & 0.005754 & 100 & 31.03269 & 68.96731 \\
\hline T15 & 48.06381 & 0.015292 & 87.69488 & 0.008381 & 100 & 42.42424 & 57.57576 \\
\hline T16 & 53.28251 & 0.013794 & 120.1871 & 0.006115 & 100 & 32.39362 & 67.60638 \\
\hline T11 & 53.26795 & 0.013798 & 125.5626 & 0.005854 & 100 & 31.25196 & 68.74804 \\
\hline T14 & 53.26465 & 0.013799 & 154.8728 & 0.004746 & 100 & 22.08751 & 77.91249 \\
\hline Average & 47.03515 & 0.016783 & 122.0293 & 0.006193 & 100 & 36.05523 & 63.94477 \\
\hline
\end{tabular}

Data of the high-pressure mercury injection shows shale pores' volume distribution presents bimodal phenomenon (which is consistent with nitrogen adsorption). The two peaks are at $6 \mu \mathrm{m}$ and 
$4 \mathrm{~nm}$ in pore size. The macropores and mesopores volume account for $85 \%$ and they provide most gas accumulation space. The bimodal phenomenon has advantages in shale gas development: The macropores maintain the high productivity in early process. The micropores may prolong the high productivity time in later development.
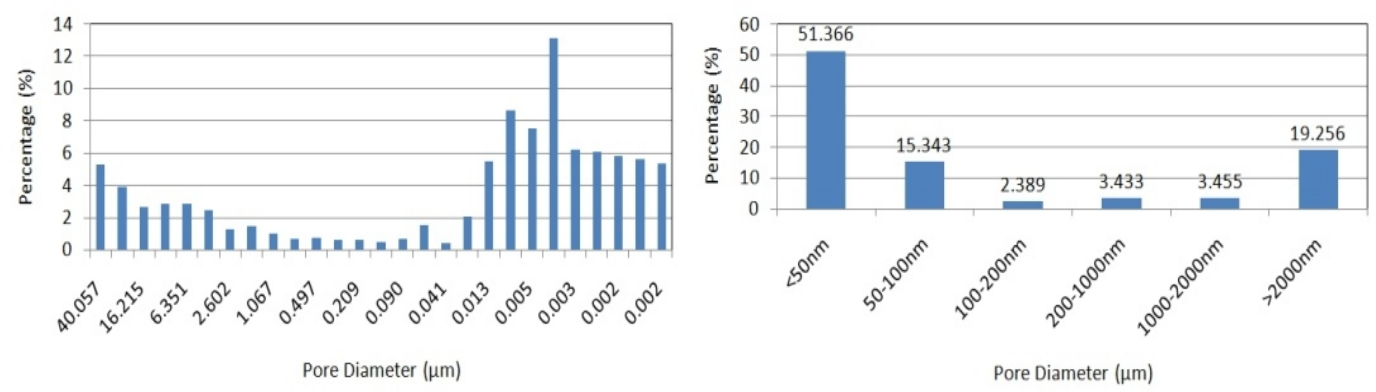

Fig.5 Pore size distribution of shale sample T1 tested by high pressure mercury injection

\section{Conclusion}

Based on the $\mathrm{N}_{2}$ adsorption and high-pressure mercury injection, there are some views about the marine-continental transitional shale of the upper Carboniferous Taiyuan Formation in eastern uplift of Liaohe depression:

(1) The shale pores mainly are nano-scale. The pores are complicated in structure, and arrange irregularly.

(2) The $\mathrm{N}_{2}$ adsorption curve is typell . The adsorption loops are three types: P1 illustrates the pores of shale mainly are one end closed pores include cylindrical pore, parallel plate pore and wedge shaped pore. P2 reflects the pores mainly are Ink bottle-shaped pores and one end closed pores. P3 reflects the pores mainly are open large pores, Ink bottle-shaped pores.

(3) The two peaks are at $6 \mu \mathrm{m}$ and $2 \mathrm{~nm}$ in pore size. The pore volume ranges from $0.0234 \mathrm{ml} / \mathrm{g}$ to $0.0527 \mathrm{ml} / \mathrm{g}$, and the average is $0.0414 \mathrm{ml} / \mathrm{g}$. The macropores and mesopores volume account for $85 \%$ and they provide most gas accumulation space. The specific surface ranges from $6.37 \mathrm{~m}^{2} / \mathrm{g}$ to $12.55 \mathrm{~m}^{2} / \mathrm{g}$, and the average is $9.56 \mathrm{~m}^{2} / \mathrm{g}$. The micropores and mesopores specific surface account for $97.86 \%$ and they enhance the adsorption capacity of shale.

\section{References}

[1]. Zhang Jinchuan, Jin Zhijun, Yuan Mingsheng. Reservoiring mecha- nism of shale gas and its distribution[J]. Natural Gas Industry,2004, 24(7):15-18.

[2]. Zou Caineng, Yang Zhi, Zhang Guosheng, et al. Conventional and unconventional petroleum "orderly accumulation": Concept and practical significance[J]. Petroleum Exploration and Development, 2014, 41(1): 14-27.

[3]. Ge Ming-na, Zhang Jin-chuan, Li Xiao-guang, et al. Gas-bearing property analysis on Upper Paleozoic shale in eastern Uplift of Liaohe Basin [J]. Fault-Block Oil Gas Field, 2012, 19(6): 722-726 (in Chinese with English abstract).

[4]. Ge Ming-na, Zhang Jin-chuan, Li Xiao-guang, et al. Evaluation on Neopaleozoic shale gas resource potential in the Eastern Salient of the Liaohe Depresion [J]. Natural Gas Industry, 2012, 32(9): 28-32.

[5]. Mao Junli, Li Xiaoguang, Shan Yansheng, et al. Shale gas accumulation conditions of Eastern Re gion of Liaohe Depression [J]. Earth Science Frontiers, 2012, 19(5): 348-355.

[6]. Ren Zhunlin, Li Xiaoguang, Wanglong, et al. Enrichment condition of Lishugou Formation shale gas and favorable area selection in eastern area of Liaohe[J]. Fault-block Oil \& Gas Field, 2013, 20(6): :704-708. 
[7]. Yu Peng. Application of widely-covered hydrocarbon generation concept to hydrocarbon accumi ulation in Eastern Uplift, Liaohe Depression[J]. Journal of Xi' an Shiyou University(Natural Scien ce Edition), 2014, 29(4): 24-30+7.

[8]. Currtis J B. Fracture shale-gas systems[J]. AAPG Bulletin, 2002, 86(11): 1921-1928.

[9]. Dong Dazhong, Zou Caineng, Li Jianzhong, et al. Resource poten- tial, exploration and development prospect of shale gas in the wholeworld[J]. Geological Bulletin of China, 2011,30(2/3):324-326.

[10]. Wang Hongyan, Liu Yuzhang, Dong Dazhong, et al. Scientific issues on effective development of marine shale gas in southern China[J]. Petroleum Exploration and Development, 2013, 40(5): 574-579.

[11]. Zou Caineng, Dong Dazhong, Wang Shejiao, et al. Geological charac- teristics, formation mechanism and resource potential of shale gas inChina[J]. Petroleum Exploration and Development, 2010,37(6):641-643.

[12]. Nie Haikuan, Bian Ruikang, Zhang Peixian, et al. Micro-types and characteristics of shale reservoir of the Lower Paleozoic in Southeast Sichuan Basin, and their effects on the gas content[J]. Earth Science Frontiers, 2014, 21(4): 331-343.

[13]. Pu Boling, Dong Dazhong, Er Chuang, et al. Favorable reservoir characteristics of the Longmaxi shale in the southern Sichuan Basin and their influencing factors[J]. Natural Gas Industry, 2013, 33(12): 41-47.

[14]. Loucks R G, Reed R M, Ruppel S C, et al. Spectrum of pore types and networks in mudrocks and a descriptive classification for matrix-related mudrocks pores [J]. AAPG Bulletin, 2012, 96(6): 1071-1098.

[15]. Zou Caineng, Zhu Rukai, Bai Bin, et al. First discovery of nano-pore throat in oil and gas reservoir in China and its scientific value[J]. Acta Petrologica Sinica, 2011, 27(6): 1857-1864.

[16]. Rouquerol J, Avnir D, Fairbridge C W, et al. Recommendations for the characterization of poros solids[J]. Pure \& Applied Chemistry, 1994, 66(8): 1739-1785.

[17]. Yan Jimin, Zhang Qiyuan,. Adsorption and Condensation-the surface and Pore of Solid[M]. Beijing: Scientific Press, 1979.

[18]. Liu Hui, Wu Shaohua, Jiang Xiumin, et al. The configuration analysis of the adsorption isotherm of nitrogen in low temperature with the lignite char produced under fast pyrolysis[J]. Journal of China Coal Society, 200530 (4):507-510.

[19]. Chen Ping, Tang Xiuyi. The research on the adsorption of nitrogen in low temperature and micro-pore properties in coal[J]. Journal of China Coal Society, 2001, 26(5): 552-556.

[20]. Yang Feng, Ning Zhengfu, Kong Detao, et al. Pore Structure of Shales from High Pressure Mercury Injection and Nitrogen Method[J]. Nutural Gas Geoscience, 2013, 24(3): 450-455. 